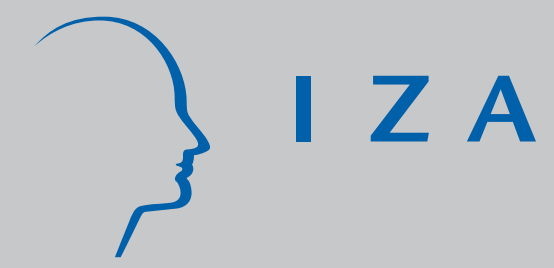

IZA DP No. 254

Learning of General Equilibrium Effects and the Unemployment Trap

Hans Gersbach

Achim Schniewind

February 2001 


\title{
Learning of General Equilibrium Effects and the Unemployment Trap
}

\author{
Hans Gersbach \\ Alfred-Weber-Institut, University of Heidelberg and IZA, Bonn \\ Achim Schniewind \\ Alfred-Weber-Institut, University of Heidelberg \\ Discussion Paper No. 254 \\ February 2001 \\ IZA \\ P.O. Box 7240 \\ D-53072 Bonn \\ Germany \\ Tel.: $+49-228-3894-0$ \\ Fax: +49-228-3894-210 \\ Email: iza@iza.org
}

This Discussion Paper is issued within the framework of IZA's research area The Welfare State and Labor Markets. Any opinions expressed here are those of the author(s) and not those of the institute. Research disseminated by IZA may include views on policy, but the institute itself takes no institutional policy positions.

The Institute for the Study of Labor (IZA) in Bonn is a local and virtual international research center and a place of communication between science, politics and business. IZA is an independent, nonprofit limited liability company (Gesellschaft mit beschränkter Haftung) supported by the Deutsche Post AG. The center is associated with the University of Bonn and offers a stimulating research environment through its research networks, research support, and visitors and doctoral programs. IZA engages in (i) original and internationally competitive research in all fields of labor economics, (ii) development of policy concepts, and (iii) dissemination of research results and concepts to the interested public. The current research program deals with (1) mobility and flexibility of labor markets, (2) internationalization of labor markets and European integration, (3) the welfare state and labor markets, (4) labor markets in transition, (5) the future of work, (6) project evaluation and (7) general labor economics.

IZA Discussion Papers often represent preliminary work and are circulated to encourage discussion. Citation of such a paper should account for its provisional character. 
IZA Discussion Paper No. 254

February 2001

\section{ABSTRACT \\ Learning of General Equilibrium Effects and the Unemployment Trap*}

We examine wage bargaining when employers and labor unions do not always take all general equilibrium effects into account but learn a steady state. If agents do hardly consider general equilibrium effects, low real wages and low unemployment results. With an intermediate view, when partial equilibrium effects are taken into account, high real wages and unemployment results, which may explain the persistence of high unemployment in Europe. If all general equilibrium effects are incorporated at once, again low real wages and low unemployment results. We thus obtain a hump-shaped relationship between the extend of feedback effects incorporated by the bargaining parties and real wages or unemployment.

JEL Classification: D58, E24, J60, L13

Keywords: Labor markets, wage bargaining, learning of general equilibrium effects, unemployment

Hans Gersbach

Alfred Weber-Institut

Universität Heidelberg

Grabengasse 14

69117 Heidelberg

Tel.: +49-6221-54 3173

Fax: +49-6221-54 3578

Email: hans@gersbach.de

\footnotetext{
*We would like to thank Martin N. Baily, Hans Haller, Gilles Saint-Paul, George Sheldon, Robert Solow, Jan Wenzelburger, conference participants at the annual meeting of the German Economic Association in Mainz 1999 and seminar participants in Heidelberg and Bonn for helpful comments and suggestions.
} 


\section{Introduction}

It is widely recognized that there are many factors underlying the high European unemployment rates, but it has been difficult to isolate specific factors and explain why high unemployment rates persist. In this paper we argue that insufficient learning of general equilibrium effects by unions and employers' associations may provide an explanation why European unemployment remains so high.

We consider wage bargaining in a sector between a labor union and an employers' association. We assume that both bargaining agents take partial equilibrium effects into account but do not or cannot always consider all feedback effects from other sectors or from the tax system when negotiating wages. After a wage agreement has been reached and general equilibrium effects have been realized, the union and the employers' association observe that unemployment is higher than assumed, because income and demand for all sectors have been negatively affected. In addition the employers' association observes that sector profits have been overestimated because prices and output are lower than expected because of general equilibrium effects. But when both parties negotiate wages again, employers' associations are prepared to make further wage concessions because they overestimate price increases again. Also, unions push again for higher wages to increase their members' wage bill because they underestimate negative feedbacks from other sectors. Hence, both bargaining agents react to negative feedback effects by agreeing for higher wages. Such repeated wage adjustments will cease when both parties do not want to change wages any more. In such a steady state, however, unemployment is persistent and much higher compared to the outcome that would occur when both parties incorporate all general equilibrium effects in the wage negotiations at once. Hence, insufficient learning of general equilibrium effects can provide an explanation why high unemployment persists.

The paper is motivated by the large literature on the European unemployment problem, reviewed briefly in the next section. Since a substantial part of the unemployment is structural in nature and, in principle, could be eliminated, it has been difficult to explain why high unemployment persists. Saint-Paul $(1994,1995)$ has shown that current labor market regulations can be explained by a political equilibrium. Coe and Snower (1997) have suggested that the importance of complementarities among labor market policies have not been sufficiently recognized. 
Our paper suggests that agents' insufficient learning of general equilibrium effects in countries with collective bargaining arrangements or minimum wage laws can provide a complementary explanation why unemployment persists. If unions and employers' associations are not able to incorporate all feedback effects from other sectors when negotiating wages, they end up in high wages and unemployment because they react to negative output, income and profit realizations by wage adjustments in the wrong direction.

The paper is organized as follows. In the next section, we relate our paper to the literature. In section 3 we introduce the model. We examine a general equilibrium model with two types of labor, low and high-skilled, and two industry sectors. The model is closed by an unemployment insurance financed by taxes on labor, i.e. the governments' budget constraint. In section 4 we first explain a bargaining process called Partial Equilibrium Bargaining (PEB). For PEB we assume that the bargaining parties recognize, and therefore take into account, only the direct effects on their sector resulting from wage setting. However, they react to general equilibrium effects in the next wage negotiation. The outcome is compared with the case called General Equilibrium Bargaining (GEB). GEB means that all general equilibrium effects are taken into account when the wage is negotiated. We show that unemployment is always higher under repeated PEB than under GEB. This means that an insufficient recognition of general equilibrium effects will not be learned when unions and employers' associations bargain repeatedly over wages. We also illustrate that the relationship between the degree of feedback effects taken into account and unemployment is not monotonical over the whole set of feedback effects. If bargaining parties were very myopic and took only the direct employment effects of wages into account without recognizing changes in product prices etc., wages and unemployment would be lower compared to PEB. Section 5 concludes.

\section{Relation to the Literature}

There is a vast literature discussing the impact of labor market institutions on unemployment that we will not try to summarize here. Surveys and detailed accounts of labor market factors as root causes of the unemployment problem in Europe can be found in Blanchard and Summers (1986), Burda and Wyplosz (1994), Layard, Jackman, and Nickell (1991), Snower (1993), Bean (1994), Krugman (1994), Franz 
(1995), Minford (1995), OECD (1995), Paque (1995), Alogoskoufis, Bean, Bertola, Cohen, Dolado and Saint-Paul (1996), Giersch (1996), Gersbach and Sheldon (1996), Lindbeck (1996), Oswald (1996), Siebert (1997), Nickell (1997). In general, unemployment has been associated with labor market factors affecting supply and demand for labor, including unemployment benefits systems, institutional settings for wage determination and minimum wages.

The main point of our paper is that insufficient learning of general equilibrium effects can considerably reinforce the negative impact of particular labor market institutions on unemployment. We show that collective wage agreements yield high unemployment under PEB while they would only create moderate unemployment under GEB.

Our paper is related to the political implementation and reform design issues. First, Saint-Paul [1994, 1995, 1998], has argued that the redistributive goals that motivate labor market institutions in Europe may be achieved at a much lower cost using more traditional tax and transfer instruments. However, the current level of regulation can be explained by a political equilibrium since there is a bias towards maintaining the status quo. Second, as argued in Coe and Snower [1997] for the labor market and in Gersbach and Sheldon [1996] for the combination of product and labor market reforms, many policies appear to be complementary. The unemployment effect of each policy is greater when it is implemented in conjunction with the other policies than in isolation. Broad packages of labor market reforms can internalize complementarities across reform steps. Third, Piketty [1998] has suggested unemployment remains high because a necessary decline of low-skilled people's wages would be associated with a low social status or human value which may not be widely accepted in the public. The results in our paper suggest that high unemployment may also be the result of insufficient learning of general equilibrium effects.

Finally, our paper is related to the literature on adaptive learning processes in game theoretic situations (for recent surveys see Young 1997, Fudenberg and Levine 1998). The learning process we employ for unions and employers' associations is similar to the best reply dynamics. There are two differences to the best reply learning models in game theoretic situations. First, the union and the employers' association bargain cooperatively (Nash bargaining), and hence they maximize a common objective function. Second, in our general equilibrium setting, both agents take the previous realizations of output and income generated in other sectors as 
given. They do not assume any particular behavior of other agents in the economy, but market outcomes. In this respect our learning process is more related to the large literature on learning in dynamic expectations models comprehensively surveyed in Evans and Honkapohja (1999).

\section{Model}

In this section, we develop a model to analyze different wage bargaining processes associated with different degrees of sophistication concerning feedback effects.

There are two types of labor: skilled and unskilled. These are the only inputs into production. In the long run, there is no loss of generality associated with neglecting capital, provided that capacity constraints are not binding and that the long-run capital stock is determined by equating the marginal product of capital with the real world interest.

There are two sectors producing good 1 and good 2. In both sectors low-skilled and high-skilled workers can be employed. The production functions are given by:

$$
\begin{aligned}
& q_{1}=A_{1} L_{1}^{\ell^{\beta_{1}^{\ell}}} L_{1}^{h^{\beta^{h}}} \\
& q_{2}=A_{2} L_{2}^{\ell^{\beta_{2}^{\ell}}} L_{2}^{h^{\beta^{h}}}
\end{aligned}
$$

Subscripts 1 and 2 denote the first and second sector, respectively. $h$ and $\ell$ denote the skill levels of workers. We assume that low-skilled workers as well as high skilledworkers are immobile across industries, i.e. they can only work in one sector. Total labor input of low-skilled workers is $L_{1}^{\ell}+L_{2}^{\ell} . L_{1}^{h}+L_{2}^{h}$ is the labor input of high-skilled workers. Labor supply of both types of labor is given by $\bar{L}_{1}^{\ell}$ and $\bar{L}_{1}^{h}$ in sector 1 and $\bar{L}_{2}^{\ell}$ and $\bar{L}_{2}^{h}$ in sector 2 . Overall labor supply amounts to $\bar{L}=\bar{L}_{1}^{\ell}+\bar{L}_{1}^{h}+\bar{L}_{2}^{\ell}+\bar{L}_{2}^{h}$. We assume that labor is supplied inelasticly. ${ }^{1}$

We assume that all types of workers have the same CES-utility function:

$$
u=\left(\alpha_{1} \cdot c_{1}^{\frac{\sigma-1}{\sigma}}+\alpha_{2} \cdot c_{2}^{\frac{\sigma-1}{\sigma}}\right)^{\frac{\sigma}{\sigma-1}}
$$

1 Our model could be complemented by a labor/leisure tradeoff. Since we focus on unemployment rather than on aggregate output, adding a labor/leisure tradeoff would not affect our basic results. 
$c_{1}$ and $c_{2}$ denote the consumption levels of good 1 and good 2, whereas $\sigma$ denotes the elasticity of substitution between the two goods. We assume that all profits accrue to the high-skilled workers, i.e. they own all firms. Each high-skilled worker owns the same share of ownership. ${ }^{2}$.

\subsection{Real Wage Rigidity and Unemployment Insurance}

In this section, we introduce the labor markets. In sector 1 , we assume that a real reservation wage exists, denoted by $\overline{r w}$ and defined as a percentage of the market clearing real wage of the low-skilled in sector 1 if no frictions are present (all wages competitive). If $\overline{r w}$ exceeds the market clearing real wages, it becomes binding for the low-skilled and unemployment occurs in the first sector. $w_{1}^{\ell}$ is then $p \cdot \overline{r w}$. A variety of regulations can cause a real wage floor: explicit minimum wages, an unemployment benefit system or institutional wage settings in sector 1 .

Wages for the low-skilled in the second sector are determined by the wage bargaining process that will be the focus of our examinations. The high-skilled labor markets we always assume to be competitive in both sectors. Labor is taxed at flat rate, denoted by $\tau$, to finance benefits for the unemployed workers. ${ }^{3}$ We assume that the unemployed obtain a fixed percentage of the wages earned by the low-skilled working in sector 1 , denoted by $u b$. Let us denote the share of unemployed workers by $\Delta$, given by:

$$
\Delta=\bar{L}_{1}^{\ell}-L_{1}^{\ell}+\bar{L}_{2}^{\ell}-L_{2}^{\ell}
$$

The government's budget constraint implies that

$$
\left(w_{1}^{\ell} L_{1}^{\ell}+w_{2}^{\ell} L_{2}^{\ell}+w_{1}^{h} L_{1}^{h}+w_{2}^{h} L_{2}^{h}\right) \cdot \tau=u b \cdot \Delta
$$

2 If shares of firms are traded, each high-skilled worker would hold the market portfolio.

3 If taxation were not distortionary, full employment and any distributional goal could be achieved by an appropriate tax scheme. Hence, the impossibility to eliminate real wage rigidities can either be explained by tax distortions or by political factors. 


\subsection{The System of Equations}

The equilibrium with wage rigidities is determined by the following system of equations. Throughout the paper we normalize the price of the first good to 1, i.e.

$$
p_{1}=1
$$

By utility maximization we receive the following demand equations for consumption:

$$
\begin{aligned}
& c_{1}=\frac{b}{p_{1}+p_{2}\left(\frac{p_{1}}{p_{2}} \frac{a_{2}}{a_{1}}\right)^{\sigma}} \\
& c_{2}=\frac{b}{p_{2}+p_{1}\left(\frac{p_{2} a_{1}}{p_{1} a_{2}}\right)^{\sigma}}
\end{aligned}
$$

$\mathrm{b}$ denotes the budget of the households. We have five different budgets. The lowskilled worker's budget consists entirely of wages (which are different in sector 1 and sector 2 in general). The budget of the high-skilled include their wages and profits. The unemployed obtain benefits $u b$. Hence we have ten demand functions for consumption. The five different budgets leading to ten demand functions for consumption are given as follows:

$$
b_{1}^{\ell}=w_{1}^{\ell} \Rightarrow c_{11}^{\ell}, c_{12}^{\ell}
$$

$c_{12}^{\ell}$ denotes the demand of low-skilled workers from sector 1 (first lower index) for good 2 (second lower index).

$$
\begin{gathered}
b_{2}^{\ell}=w_{2}^{\ell} \Rightarrow c_{21}^{\ell}, c_{22}^{\ell} \\
b_{1}^{h}=w_{1}^{h}+\left(\pi_{1}+\pi_{2}\right) /\left(L_{1}^{h}+L_{2}^{h}\right) \Rightarrow c_{11}^{h}, c_{12}^{h}
\end{gathered}
$$




$$
\begin{gathered}
b_{2}^{h}=w_{2}^{h}+\left(\pi_{1}+\pi_{2}\right) /\left(L_{1}^{h}+L_{2}^{h}\right) \Rightarrow c_{21}^{h}, c_{22}^{h} \\
b^{u}=u b \Rightarrow c_{1}^{u}, c_{2}^{u}
\end{gathered}
$$

The upper index u stands for the unemployed. Profit functions of the firms are sales minus costs, augmented by the tax wedge. Total labor costs for a firm consist of the wage bill and the tax expenditures. Therefore:

$$
\begin{aligned}
& \pi_{1}=p_{1} q_{1}-w_{1}^{\ell}(1+\tau) L_{1}^{\ell}-w_{1}^{h}(1+\tau) L_{1}^{h} \\
& \pi_{2}=p_{2} q_{2}-w_{2}^{\ell}(1+\tau) L_{2}^{\ell}-w_{2}^{h}(1+\tau) L_{2}^{h}
\end{aligned}
$$

Firms are price takers in both sectors. We obtain the first order conditions for profit maximization of firms in sector 1 .

$$
\begin{gathered}
w_{1}^{\ell}(1+\tau)=p_{1} A_{1} L_{1}^{h} \beta_{1}^{\ell} L_{1}^{\ell^{\ell \ell-1}} \\
w_{1}^{h}(1+\tau)=p_{1} A_{1} L_{1}^{\beta^{\ell}} \beta_{1}^{h} L_{1}^{h^{\beta_{1}^{h}-1}}
\end{gathered}
$$

Similarly, we obtain the first order conditions for profit maximization of firms in sector 2 under perfect competition

$$
\begin{gathered}
w_{2}^{\ell}(1+\tau)=p_{2} A_{2} L_{2}^{h} \beta_{2}^{\ell} L_{2}^{\ell^{\beta_{2}^{\ell}-1}} \\
w_{2}^{h}(1+\tau)=p_{2} A_{2} L_{2}^{\beta^{\ell / 2}} \beta_{2}^{h} L_{2}^{h^{\beta_{2}^{h}-1}}
\end{gathered}
$$


Market clearing for good 1 implies:

$$
L_{1}^{\ell} \cdot c_{11}^{\ell}+L_{2}^{\ell} \cdot c_{21}^{\ell}+L_{1}^{h} \cdot c_{11}^{h}+L_{2}^{h} \cdot c_{21}^{h}+\Delta \cdot c_{1}^{u}=q_{1}
$$

We will choose our parameters so that the real reservation wage will be binding and thus the labor market for low-skilled workers in sector 1 will not clear. This mirrors the fact that there are non competitive wages in many industries. In sector 2 the negotiated wage for low-skilled will not clear the labor market either, whereas labor market clearings for high skilled workers hold and are given by:

$$
\begin{aligned}
& \bar{L}_{1}^{h}=L_{1}^{h} \\
& \bar{L}_{2}^{h}=L_{2}^{h}
\end{aligned}
$$

The true price index is defined by [see e.g. Dixon 1995]

$$
p=\left[\left(\frac{a_{1}^{\sigma}}{a_{1}^{\sigma}+a_{2}^{\sigma}}\right) \cdot p_{1}^{(1-\sigma)}+\left(\frac{a_{2}^{\sigma}}{a_{1}^{\sigma}+a_{2}^{\sigma}}\right) p_{2}^{(1-\sigma)}\right]^{\left(\frac{1}{1-\sigma}\right)}
$$

This price index guarantees that changes in prices do not affect households' utility as long as real incomes are kept constant. Nominal wages for low-skilled workers in sector 1 are given by:

$$
w_{1}^{\ell}=\overline{r w} \cdot p
$$

Unemployment benefits $u b$ are defined as a fraction $s$ of the minimum wages for the low-skilled in sector $1,0<s \leq 1$.

$$
u b=s \cdot \overline{r w} \cdot p
$$


Unemployment is given by:

$$
\Delta=\bar{L}_{1}^{\ell}-L_{1}^{\ell}+\bar{L}_{2}^{\ell}-L_{2}^{\ell}
$$

Labor is taxed at a flat rate in order to finance a transfer to the unemployed. The tax rate is determined by the condition that the government's budget must be balanced:

$$
\left(w_{1}^{\ell} L_{1}^{\ell}+w_{2}^{\ell} L_{2}^{\ell}+w_{1}^{h} L_{1}^{h}+w_{2}^{h} L_{2}^{h}\right) \cdot \tau=u b \cdot \Delta
$$

The only variable that is not yet specified in an equation is the wage resulting from the bargaining process in the second sector.

\subsection{The Wage Bargaining Process in Sector 2}

We assume that wages in sector 2 are determined by collective bargaining between a union and an employers' association. ${ }^{4}$ The union has the following objective function

$$
\Gamma_{u}=\frac{w_{2}^{\ell}-u b}{p} \cdot L_{2}^{\ell}
$$

$\Gamma_{u}$ results from utility maximization of the labor union for its members (see Manzini [1998]). It is the excess of the union member's utility in case of agreement over the utility in case of disagreement in the negotiation.

The objective of the employers' federation is to maximize real profits:

$$
\Gamma_{e}=\frac{\pi_{2}}{p}
$$

We assume that wages are determined by the Nash-bargaining solution. The general objective function is the weighted geometric mean of the two single objective functions.

4 Manzini [1998] provides a recent survey of collective bargaining processes. Schmidt et. al. (1994) point out how general equilibrium effects through migration can affect wage setting. 


$$
\Gamma=\Gamma_{u}^{\delta} \cdot \Gamma_{e}^{1-\delta}
$$

$\delta$ is the union's bargaining power $(0 \leq \delta \leq 1)$. $1-\delta$ is the bargaining power of the employers' association.

The key issue is which feedback loops labor unions and industry associations will take into account when they agree upon wages. We consider three different levels of sophistication of the bargaining parties. The first possibility is that all general equilibrium effects are taken into account by the bargaining agents. Hence, changes in output, prices in all sectors and changes in taxes are calculated and enter the common objective. Mathematically this implies that we first have to solve the system of equations $6,9,10,11,12,13,16,17,18,19,20,21,22,23,24,25,26$, 27 for the unknown variables $w_{1}^{\ell}, w_{1}^{h}, w_{2}^{h}, u b, L_{1}^{\ell}, L_{2}^{\ell}, L_{1}^{h}, L_{2}^{h}, p 1, p 2, p, c_{1}^{u}, c_{2}^{u}, c_{11}^{\ell}$, $c_{12}^{\ell}, c_{21}^{\ell}, c_{22}^{\ell}, c_{11}^{h}, c_{12}^{h}, c_{21}^{h}, c_{22}^{h}, \Delta, \tau$ as functions of $w_{2}^{\ell}$. The solved variables must be inserted in the objective function $\Gamma$ of the bargaining parties. The Nash Bargaining Solution (NBS) $w_{2}^{\ell}$ is then determined as the wage that maximizes $\Gamma$. Note that the resulting equilibrium is the one that really maximizes the objective function $\Gamma$, since these equilibrium values will actually be realized. Under this bargaining procedure agents take into account all general equilibrium effects that occur when a wage in one sector is changed. We call this bargaining process General Equilibrium Bargaining (GEB).

We next examine what happens in the probably more realistic case that agents do not or cannot take into account all feedback effects resulting in the general equilibrium. One might think that unions and industry associations only take into account the employment effect $L_{2}^{\ell}\left(w_{2}^{\ell}\right)$, i.e. that only the change in employment $L_{2}^{\ell}$ associated with a change in wages $w_{2}^{\ell}$ is considered, whereas all other variables are assumed to stay constant. The wage bargaining process based on this myopic assessment of the economy is called Myopic Bargaining (MB).

Probably the most plausible case is that agents only take the most direct feedbacks into account. Let's look again at the objective function of the union and the industry association when the profit $\pi_{2}$ is inserted.

$$
\Gamma_{u}=\frac{w_{2}^{\ell}-u b}{p(p 1, p 2)} \cdot L_{2}^{\ell}
$$




$$
\Gamma_{e}=\frac{p_{2} q_{2}-w_{2}^{\ell}(1+\tau) L_{2}^{\ell}-w_{2}^{h}(1+\tau) L_{2}^{h}}{p(p 1, p 2)}
$$

We consider the case where the union and the employers' association take only the direct effects of the negotiated wage into account, i.e. the effects that take place directly in their sector. By doing so the bargaining parties take into account not only the employment effect $L_{2}^{\ell}$ of the negotiated wage $w_{2}^{\ell}$, but also the price effect $p_{2}$ (and thereby $p$ ) and the high-skilled wage effect $w_{2}^{h}$. The tax rate $\tau$ and the unemployment benefits $u b$ as well as all other variables are considered (by the bargaining agents) to stay constant. Only the interactions between $w_{2}^{\ell}, L_{2}^{\ell}, p 2$ (and thereby $\mathrm{p}$ ) and $w_{2}^{h}$ are taken into account by the wage setters. The bargaining process based on this way of assessing the feedbacks from wage setting will be called partial equilibrium bargaining (PEB).

For $\mathrm{MB}$ and $\mathrm{PEB}$ we assume that not all general equilibrium effects are taken into account, i.e. only a few feedback effects are incorporated whereas some or most of the economic variables are considered to stay constant. However, wage setters react to general equilibrium development by renegotiating wages. This implies that the analogon to the static solution under GEB is a dynamic adjustment process for PEB and $\mathrm{MB}$ with a starting point and an endpoint. An endpoint is a constellation of wages, prices, employment, output and consumption such that unions and employers do not want to adjust wages anymore and good markets are in equilibrium. Such a steady state is called a PEB equilibrium or MB equilibrium (depending on the nature of the bargaining process). The following figure illustrates the dynamic adjustment process for $\mathrm{PEB}$, under which the bargaining parties assume that data in sector 1 and the tax rate of the preceding equilibrium stay constant.

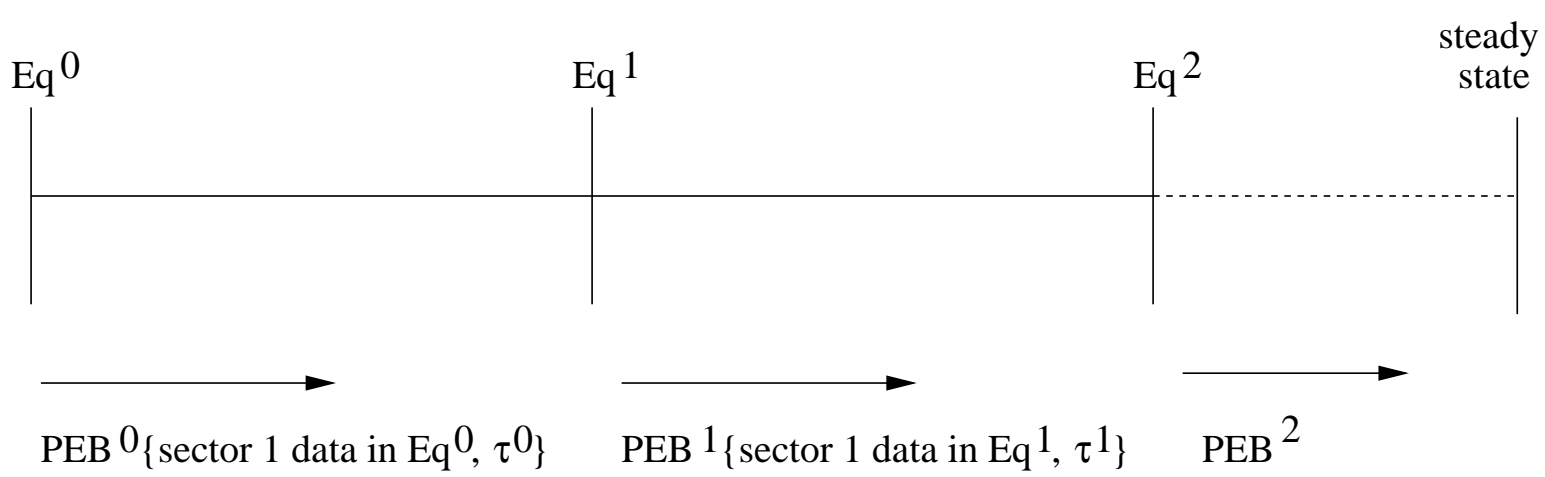


Mathematically this means for the PEB case that the three equations that determine $L_{2}^{\ell}, p_{2}$ and $w_{2}^{h}$ (equations 18,19,20) are solved simultaneously (each depending on $w_{2}^{\ell}$ ) and inserted in the objective function $\Gamma$. In the MB case, only $L_{2}^{\ell}\left(w_{2}^{\ell}\right)$ is calculated from equation 18 and inserted in $\Gamma$. After that, the constants of the starting point equilibrium are inserted in the objective function, and now the wage $w_{2}^{\ell}$ is calculated, which maximizes $\Gamma$.

\section{Results}

\subsection{Simulation Results for PEB and GEB}

The preceding section outlined the general equilibrium relationships between wages and unemployment. In this section we calibrate the model and examine how the different circumstances under which wages are negotiated affect unemployment. Given the model's simplicity, it is not easy to estimate what the parameter values should be. However, as we will discuss in the last section, the results are very robust across a wide range of variations of the parameters. We consider the following parameter constellation (see table 1):

rwfactor denotes the factor, the low-skilled real wage in sector 1 in the benchmark model without frictions (all wages competitive) is multiplied with, for the model with rigidities. In this benchmark solution, the proportion of skilled to unskilled workers is 2 to 3 . Although there is no clear-cut way to calibrate skill proportions in a two skill level economy, an estimate of around $1 / 2$ is an average of wage or education considerations [see Saint-Paul 1994]. The production function parameters were calibrated so as to imply $\frac{w^{\ell}}{w^{h}}$ to be around $1 / 2(1 / 3$ if no frictions are present in the economy). Note that the overall income differences are larger since the highskilled people are owners of the firms. The overall income of the high-skilled people is 3 to 4 times higher than that of the low-skilled people. Moreover, we focus on an elasticity of substitution of 2 in the utility function between the two goods.

As already mentioned, we need starting points for $\mathrm{PEB}$ and $\mathrm{MB}$, that is we need a market equilibrium we can start with. We first analyze PEB. In an economy with PEB, the dynamics runs as follows: The economy starts with any market equilibrium and the agents in sector 2 negotiate by considering the variables in other sectors as constant. They only take into account the interactions between wage, employment, 
Table 1:

\begin{tabular}{|l|l|}
\hline Parameters & Values \\
\hline \hline$\alpha_{1}$ & 0.5 \\
$\alpha_{2}$ & 0.5 \\
$\sigma$ & 2 \\
$A_{1}$ & 1 \\
$\beta_{1}^{\ell}$ & $\frac{2}{9}$ \\
$\beta_{1}^{h}$ & $\frac{4}{9}$ \\
$A_{2}$ & 1 \\
$\beta_{2}^{\ell}$ & $\frac{2}{9}$ \\
$\beta_{2}^{h}$ & $\frac{4}{9}$ \\
$\bar{L}_{1}^{\ell}$ & 30 \\
$\bar{L}_{2}^{\ell}$ & 30 \\
$\bar{L}_{1}^{h}$ & 20 \\
$\bar{L}_{1}^{h}$ & 20 \\
$r w f$ actor & 1.1 \\
$s$ & 0.6 \\
$\delta$ & $1 / 3$ \\
\hline
\end{tabular}

price and high-skilled wages in sector 2 . Then the wage maximizing the objective function is determined. Based on this new wage in sector 2 , a new market equilibrium is determined. In the next step, PEB based on this new market equilibrium takes place, leading to a new wage, followed by a new market equilibrium and so on.

The question arises, if this procedure converges and if so, where does it converge to? To answer this question look at figure 1: On the horizontal and vertical axes wage levels $w_{2}^{\ell}$ are shown. The two curves represent the following relationships. The first line takes a specific wage on the abscissa, calculates the equilibrium (prices, output, ..), and then derives the PEB wage associated with the calculated equilibrium values as starting point. The curve represents all combinations of wages generating equilibrium values as starting points and PEB wages. The other curve is the identity (Id). From the fact that the identity has got a steeper slope than the other curve we can conclude that the point of intersection is a stable fix point. This means that repeated PEB approaches the wage associated with the intersection. The fix point is the PEB equilibrium.

In figure 2 we have first calculated the equilibria based on the wages on the abscissa and have then inserted them in the objective function. The wage corresponding 
to the maximum of the objective function is the one the bargaining parties would choose in a world where all general equilibrium effects were taken into account. This is the GEB result, i.e. the wage that maximizes the objective function, when all feedback effects are taken into account. Surprisingly, if we compare figure 1 and figure 2, we see that the wage associated with a PEB equilibrium lies above the wage under GEB.

To find out the reason for the behavior under PEB compared with GEB, we next analyze the objective functions. In figure 3 we have plotted the general objective functions against the wage. One curve is the objective function under GEB as in the figure before. The other curve is the objective function under PEB based on the equilibrium that corresponds to the maximum of the objective function under GEB (this means we take the values of this maximum as the starting point for PEB). As we see, the agents tend to agree on higher wages under PEB starting from the optimal point of GEB. Note that at the true optimal point (the maximum of the GEB objective function) the curves intersect. This happens because at this point all the variables considered to be constant under PEB have the values also realized under GEB. So when these variables are inserted into the objective function, the value of the objective function is of course the same as under GEB, where these values occur just in the equilibrium corresponding to the maximizing wage.

In the next step we further analyze the joint objective function $\Gamma$ by looking at $\Gamma_{u}$ and $\Gamma_{e}$ separately. In figure $4, \Gamma_{u}$ under GEB and PEB are plotted against the wage, again using the maximum of $\Gamma$ under GEB as the starting point for PEB. The result is that for high wages, $\Gamma_{u}$ under PEB lies above $\Gamma_{u}$ under GEB. This implies that, from the PEB point of view, the unions push for higher wages compared to GEB (recognizing all general equilibrium effects of the economy). For low wages it is just the other way round.

In figure $5, \Gamma_{e}$ under GEB and PEB (always with the maximum of $\Gamma$ under GEB as the starting point) are plotted against wages. We can observe a pattern similar to the figure before: The objective function of the industry association $\Gamma_{e}$ under PEB lies above $\Gamma_{e}$ under GEB for high wages. This implies that employers do not realize the negative consequences of high wages under $\mathrm{PEB}$ as much as they would do under GEB. So they are more easily prepared to make wage concessions under PEB than under GEB. Note that the curves always intersect at the starting point for PEB, namely the wage, that maximizes the joint objective function $\Gamma$ under GEB. 
The question now is: Why do employers and unions tend to agree on higher wages when they fail to consider all general equilibrium effects at once? In figure 6 and 7 we have plotted two of the important variables, namely employment $L_{2}^{\ell}$ and price $p_{2}$ in sector 2. In figure 6 , one of the curves shows the employment that will actually be realized associated with a certain wage in market equilibrium. This is what unions and employers see under GEB, when they have the whole picture of the economy in mind. The other curve is the employment expected by wage setters with their PEB view considering only the interactions of $w_{2}^{\ell}, L_{2}^{\ell}, p_{2}$ and $w_{2}^{h}$ (the starting point is again the maximum of the GEB objective function). If we compare the two curves, we observe that with increasing wages employment decreases more in market equilibrium than the negotiating parties think under their PEB view.

The reason for this phenomenon is as follows: Under PEB, the bargaining parties recognize the first decrease of employment associated with high wages. But what they do not realize is that with lower employment real income in the second sector decreases as well. This in turn implies a decline in demand for good 2 and good 1. Because of the high negotiated wage in sector 2 and the real wage rigidity in sector 1 , employment in both sectors decreases even more. This again implies a further decline in income and therefore in demand for both goods, leading to a further decline in employment and so on. Furthermore, because unemployment is increasing, the tax rate to finance the unemployed also increases, leading to higher gross wages, implying a further decline in employment, leading to more unemployment, which in turn implies higher tax rates and so on until the new market equilibrium is reached. As we see, employment in a market equilibrium associated with a high wage is much lower than expected by the bargaining parties under PEB.

In figure 7 , the price of good 2 is plotted against the low-skilled wage in sector 2 . We can observe that the price is overestimated under PEB. The real price (also expected in the GEB view) is lower for high wages. The argumentation for this effect is the following: Because of the decline of employment in sector 2, production of good 2 also declines, which in turn increases the price $p_{2}$ compared to the other price $\left(p_{1}\right)$. This is also recognized under PEB, as well as the fact that an increasing $p_{2}$ also increases the profits of the firms. But what is not seen is that with high wages in sector 2 not only employment in sector 2 but also in sector 1 decreases because of the decline in demand for both goods. This in turn implies that also production of good 1 declines, thereby raising the price of good 1 compared to good 2 , so that the 
rise of $p_{2}$ relative to $p 1$ is not as big as expected under PEB.

The underestimation of the negative employment effect and the overestimation of the positive price effect associated with high wages both lead to the higher values of the objective functions under PEB and thereby to a higher wage agreement, which in turn implies more unemployment.

\subsection{Simulation Results for MB}

In this section we will complete our discussion by studying Myopic Bargaining (MB). In an economy with MB, the dynamics is similar as under PEB: The economy starts with any market equilibrium and the agents in sector 2 negotiate by considering most of the economic variables in other sectors as constant and by taking into account only the interactions between wage and employment in sector 2 . The wage maximizing the objective function as the result of the bargaining is now implemented. Based on this new wage in sector 2 a new market equilibrium is determined. In the next step, MB based on this new equilibrium takes place leading to a new wage followed by a new market equilibrium and so on.

The question that arises is again whether this procedure converges and if so where to? To analyze this, consider figure 8 which has wages in sector 2 on both axes: We have again calculated the general equilibria values resulting from the wages on the abscissa. These general equilibrium values have been taken as starting points to calculate the $\mathrm{MB}$ outcome, i.e. the negotiated wages, which, together with the starting wages, generate one curve in the figure. The other curve is the identity (Id). From the fact that the identity has a steeper slope than the other curve we can again conclude that the point of intersection is a stable fix point. This means the wage associated with the point of intersection will be the wage the economy converges to in a MB equilibrium.

In figure 9 we have first calculated the market equilibria based on the wages on the abscissa and have then inserted the equilibrium values in the objective function. The wage corresponding to the maximum is the one the bargaining parties would choose in a world where all general equilibrium effects would be taken into account. This is the GEB result (see figure 2). Surprisingly, if we compare figure 8 and figure 9 , we see that the wage the economy converges to under MB now lies below the wage under GEB. Why does this happen? The answer in this case is very simple: Under 
$\mathrm{MB}$, the bargaining agents do not take the positive price effect associated with high wages into account. That is, high wages lead to low employment and therefore low output, which in turn results in a high price of good 2. By ignoring this positive effect of high wages, the employers do not realize the positive effects on the profits. So they expect their objectives to go down more strongly with high wages than it is actually the case, implying that they are not ready for high wage concessions. This in turn leads to an agreement on a lower wage than the wage that would maximize the joint objective function.

\section{Conclusions and Extensions}

We have developed a general equilibrium model in order to study how different learning abilities of agents affect wage negotiations and unemployment. We have shown that a partial equilibrium view of the economy leads to high wages and unemployment. In contrast, if employers associations and unions take all general equilibrium effects of the economy into account, then low wages and low unemployment results. The conclusions from the paper provide an additional argument why industry sector specific collective wage agreements can be detremental for unemployment. However, the relationship between the extent to which feedback effects are taken into account and unemployment is not monotonical over the whole set of feedback effects. If bargaining parties were very myopic and would only take the direct employment effects of wages into account without recognizing changes in product prices etc., wages and unemployment would be lower compared to the outcome of the partial equilibrium view.

The results in this paper have some similarities to a well known result of labor economics, namely the observance that in an economy with very decentralized wage negotiations wages and unemployment are quite low, in an economy with more centralized wage bargaining wages and unemployment are high, and in economies with totally centralized wage settings wages and unemployment are again quite low (Calmfors and Driffill [1988]). Whereas Calmfors and Driffill vary the size of sectors and thus the degree of bargaining centralization, we vary the degree of farsightedness, obtaining also a hump-shaped curve for real wages and unemployment, respectively. The similarities to the theoretical results of Calmfors and Driffill could be interpreted in the way that different degrees of centralization are associated 
with different degrees of farsightedness of agents: Agents acting at the firm level hardly care about general equilibrium effects. On the other hand, ignoring general equilibrium effects when wages are set at a very centralized level (for instance for a whole economy) would produce large errors. Therefore it is likely that general equilibrium effects are taken into account in this case. At intermediate levels it is plausible that only partial equilibrium effects are considered by the bargaining parties.

If we consider our intermediate case as the most plausible for many European countries such as Germany, then insufficient recognition of general equilibrium effects can explain, why we do not see more forceful moves to reforms in labor and product markets. Even when unions and employers react to general equilibrium effects by adaptive learn behavior they may end up with high wages and unemployment in wage bargaining procedures. 
Figure 1: Convergence of PEB

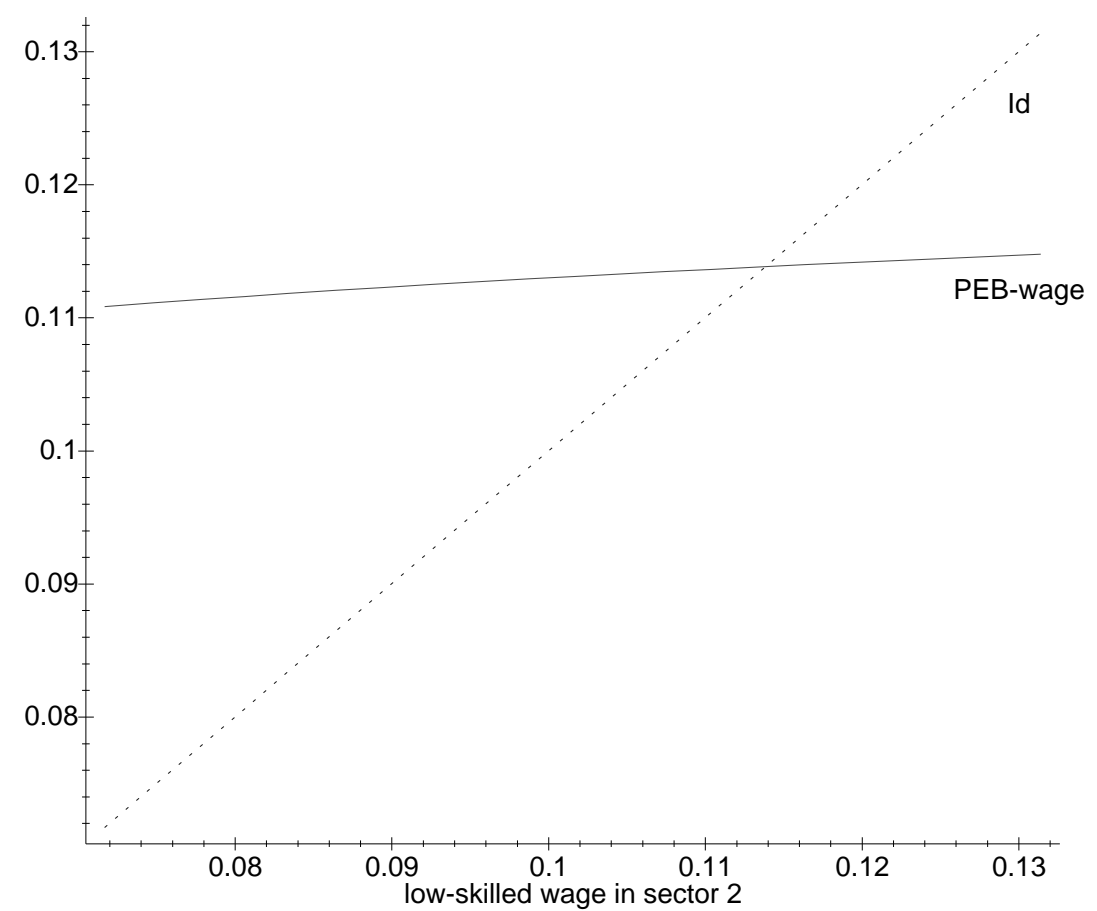

Figure 2: GEB Objective Function

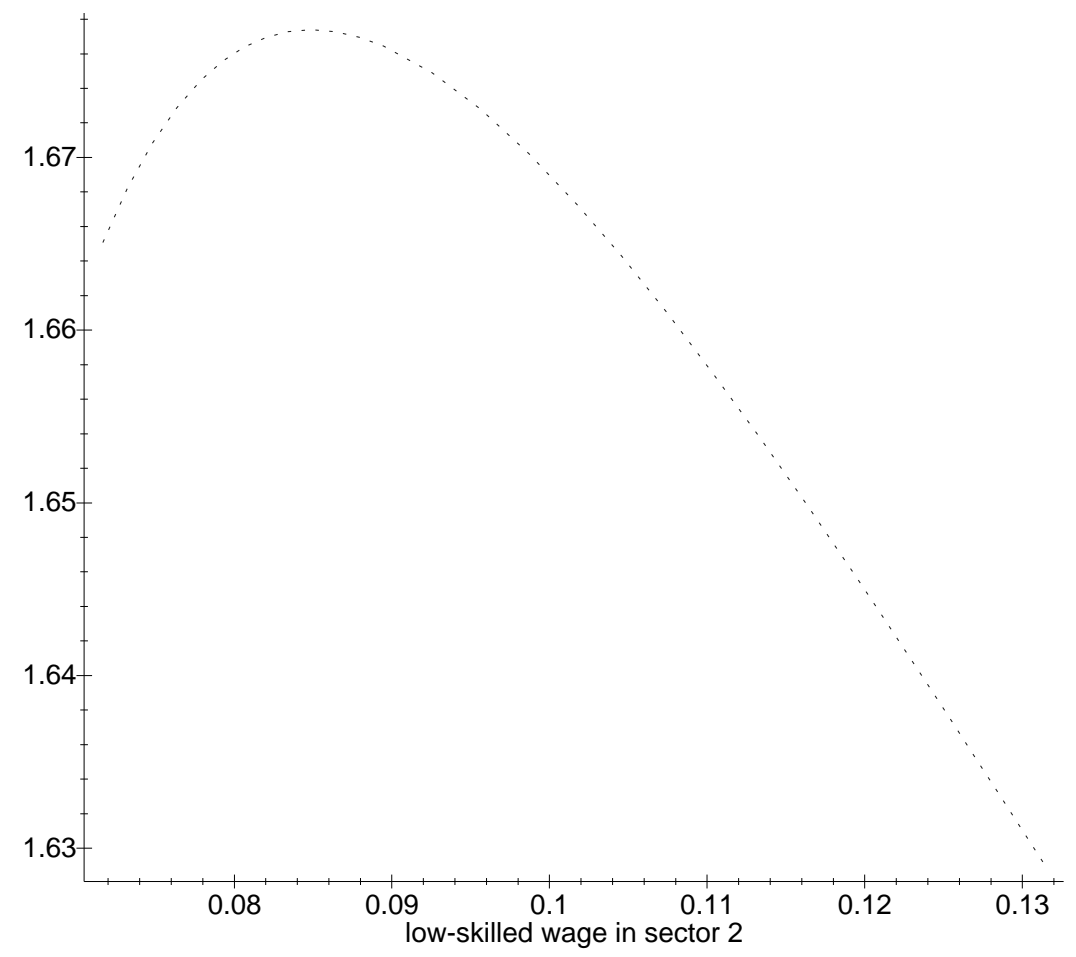


Figure 3: Objective Functions GEB / PEB

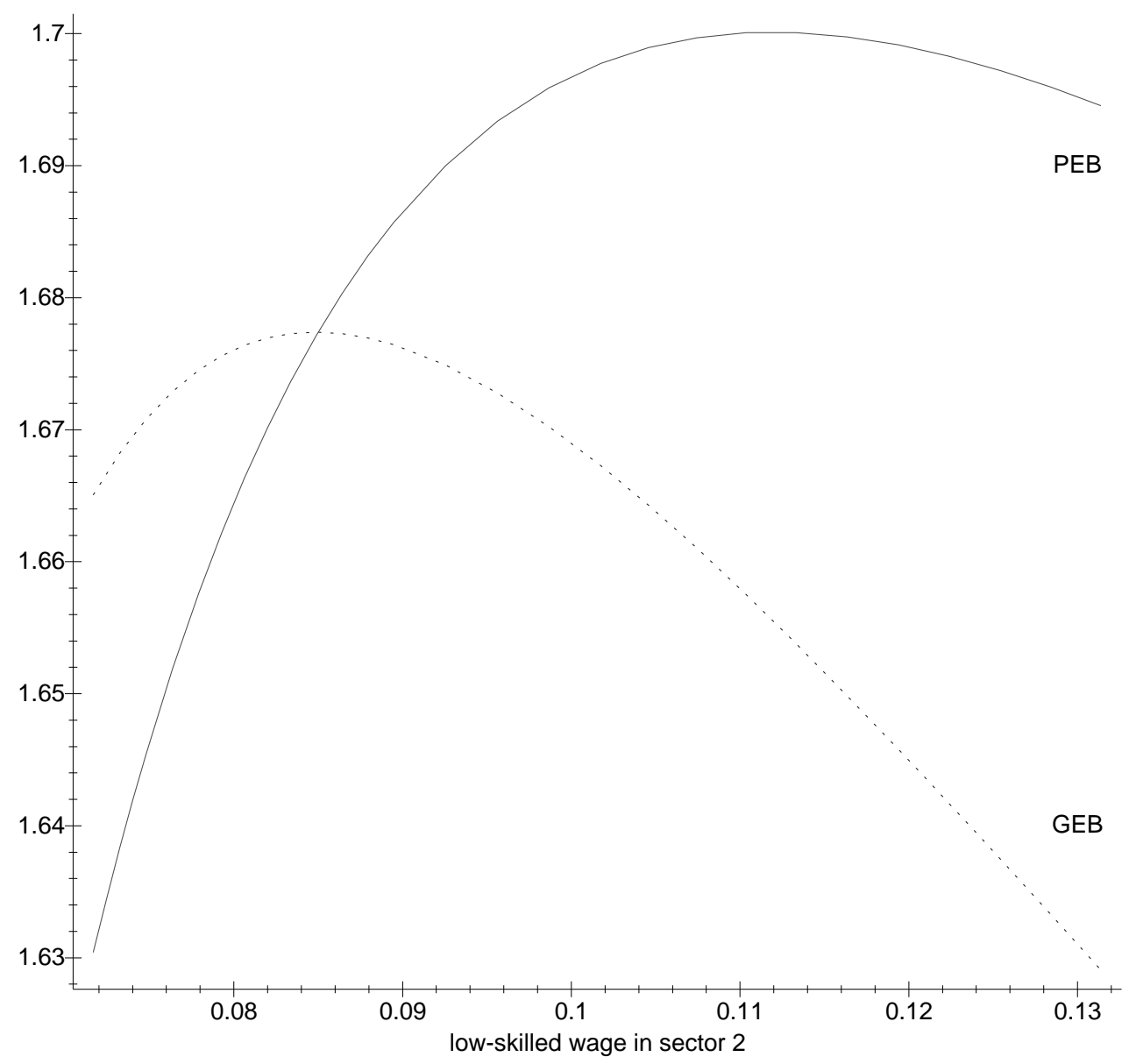


Figure 4: Union Objective Functions GEB / PEB

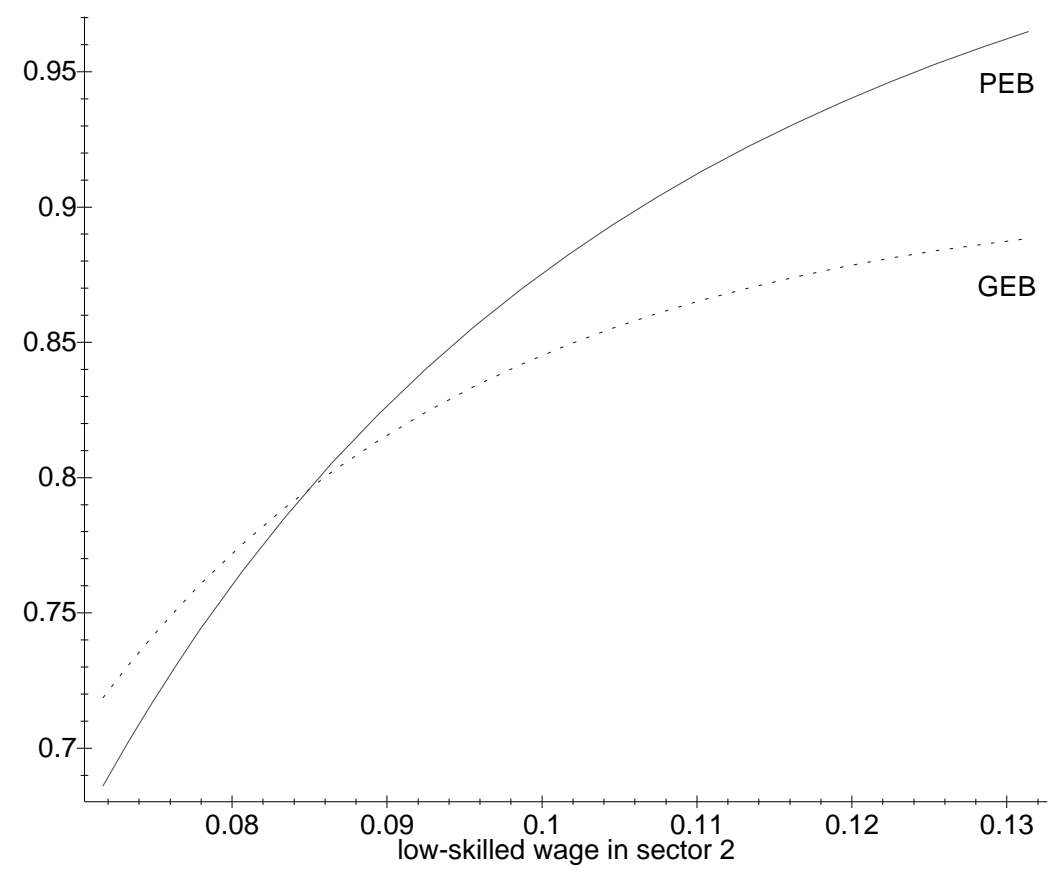

Figure 5: Employer Association Objective Functions GEB / PEB

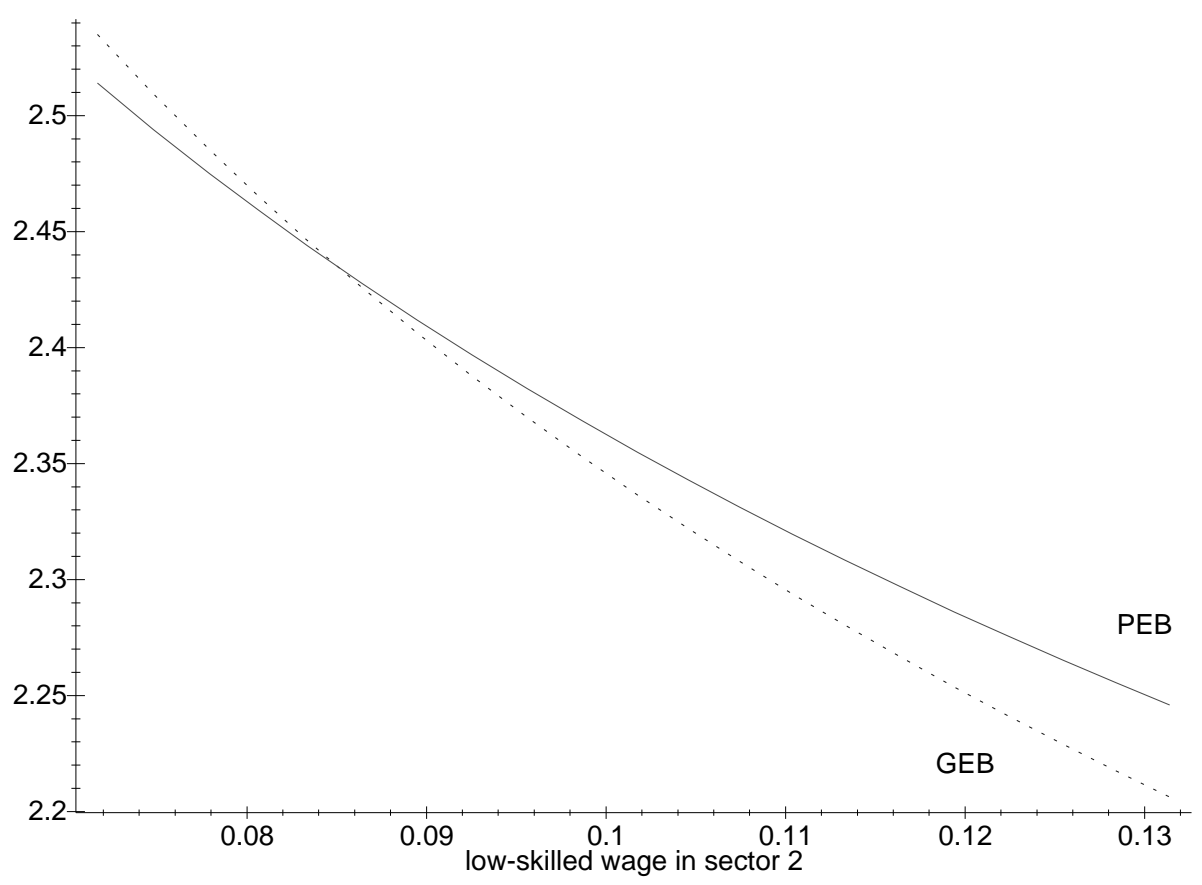


Figure 6: Low-Skilled Employment in Sector 2 GEB / PEB

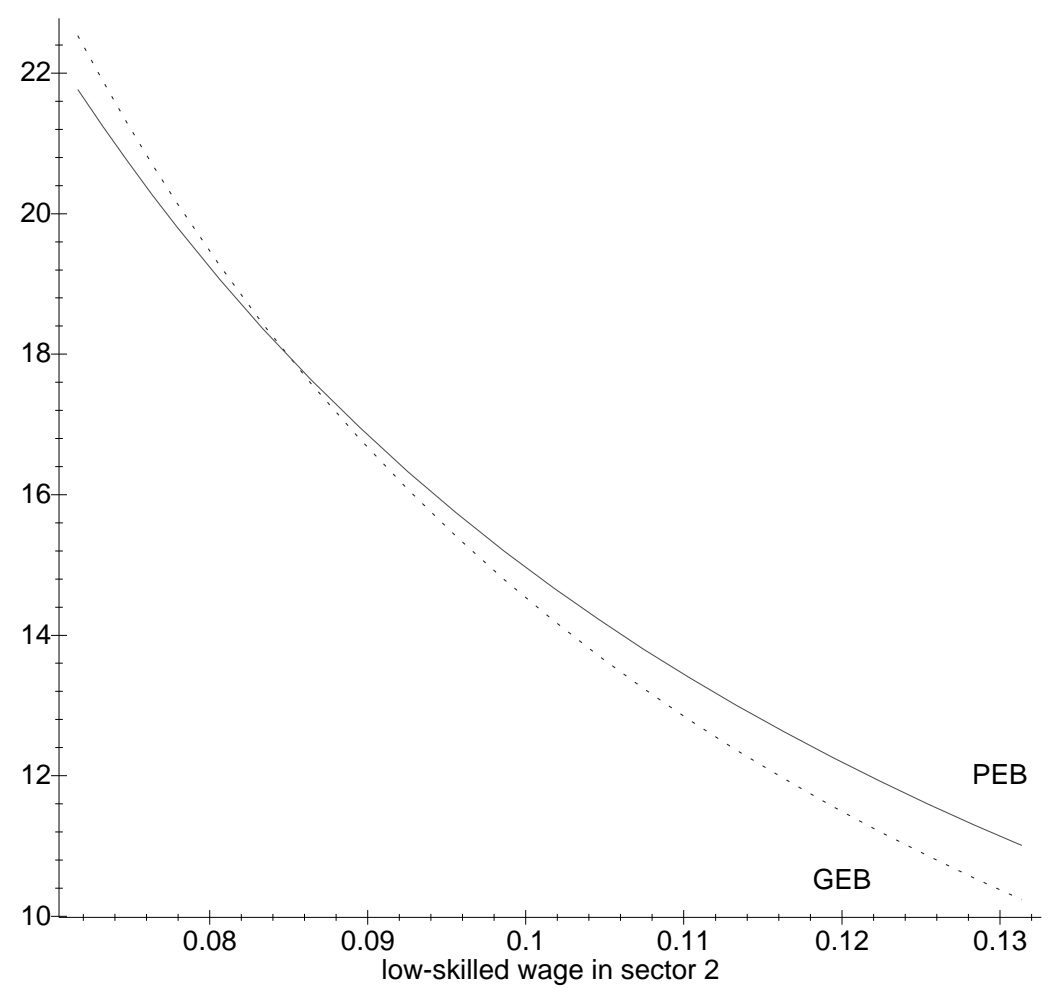

Figure 7: Price of Good 2 GEB / PEB

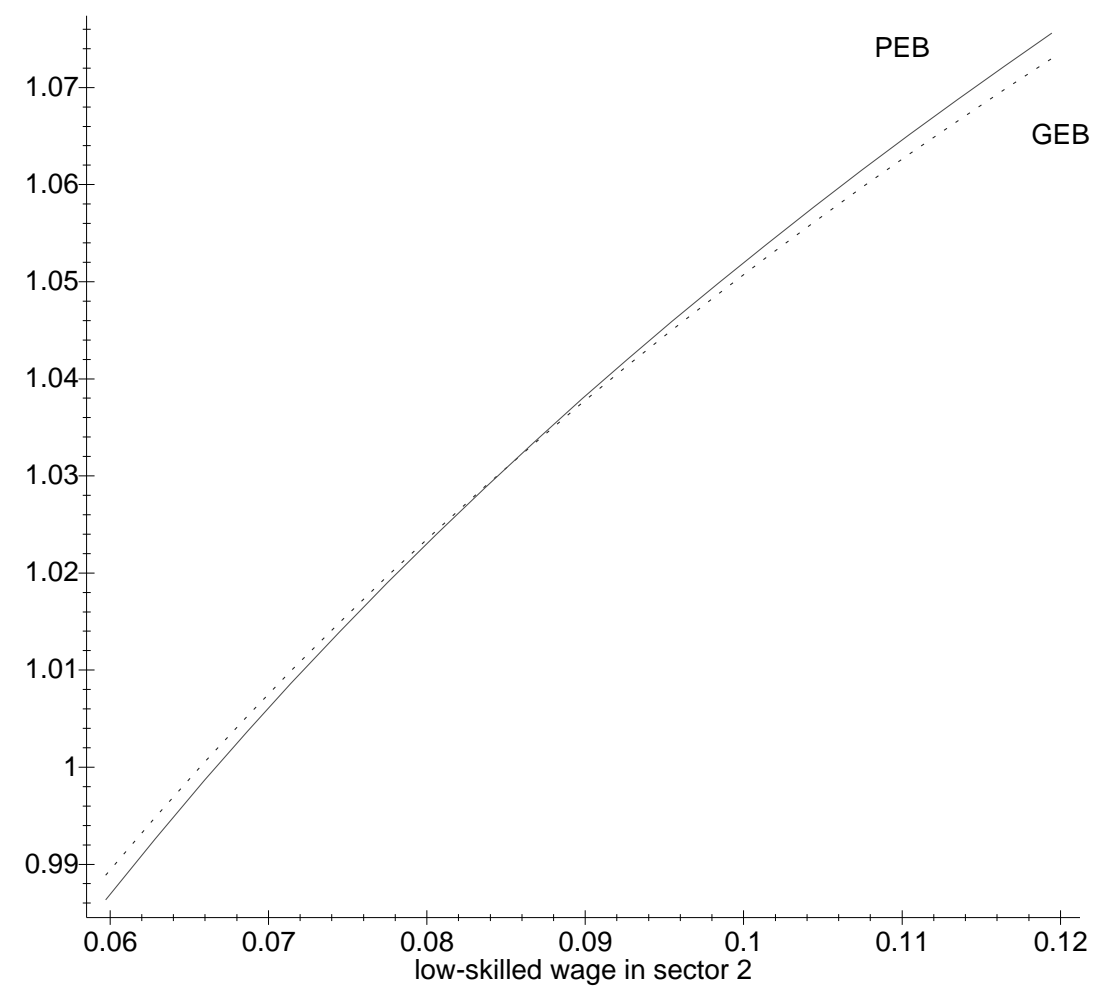


Figure 8: Convergence of $\mathrm{MB}$

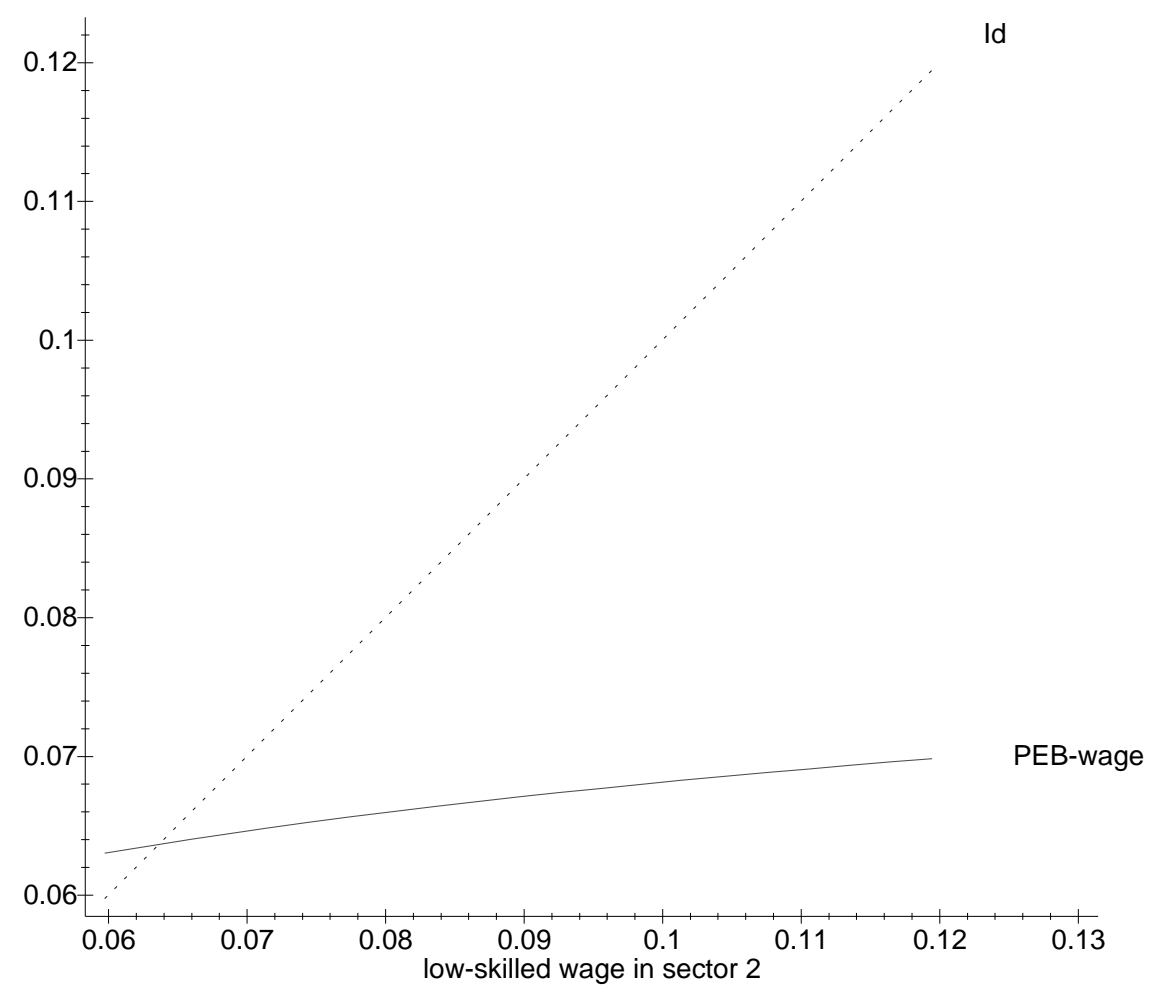


Figure 9: GEB Objective Function

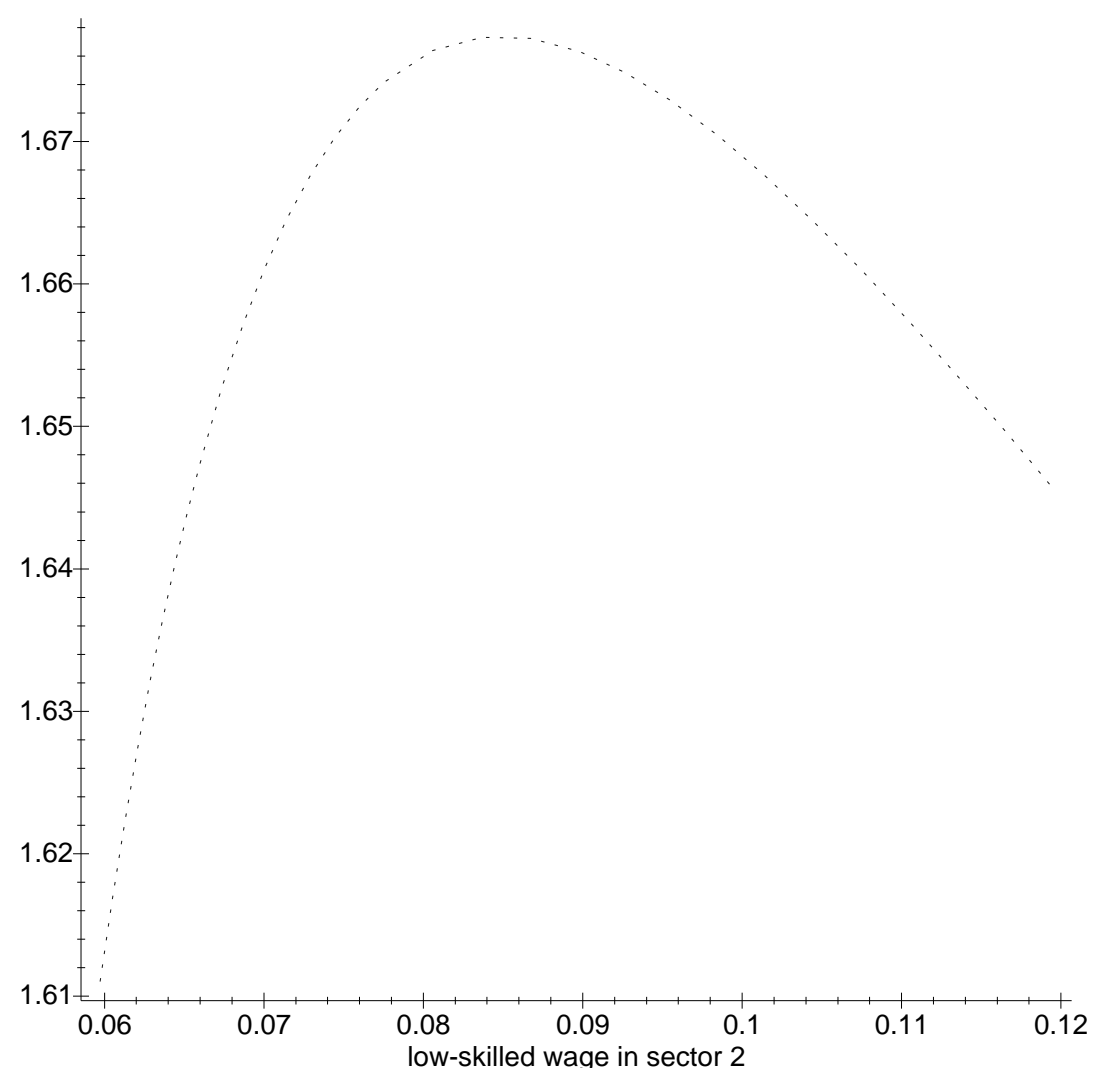




\section{References}

[1] Alogoskoufis, G., C. Bean, G. Bertola, D. Cohen, J. Dolado, G. Saint-Paul (1996): "Unemployment: Choices for Europe", Centre for Economic Policy Research.

[2] Bean, Charles R. (1994): "European Unemployment: A Survey", Journal of Economic Literature, Vol.XXXII, pp. 573-619.

[3] Blanchard, O. J., Summers, L. H. (1986): "Hysteresis and the European Unemployment Problem", NBER, Macroeeconomics Annual, 1, pp. 15-78.

[4] Burda, M., Wyplosz C. (1994): "Gross Job and Worker flows in Europe", European Economic Review, 38, 1287-1315.

[5] Calmfors, L., J. Driffill (1988): "Bargaining Structure, Corporatism and Macroeconomic Performance", Economic Policy, 6, 14-61.

[6] Coe, D. T. and Snower, D.J.(1997): "Policy Complementaries: The Case for Fundamental Labor Market Reform", IMF Staff Papers, Vol.44, No. 1.

[7] Dixon, H.D., Rankin (1995): "The New Macroeconomics: Imperfect Markets and Policy Effectiveness", Cambridge University Press, Cambridge, UK.

[8] Evans, G.W., Honkapohja, S. (1999): "Learning Dynamics", in Taylor, J., Woodford, M.: Handbook of Macroeconomics, Elsevier, Amsterdam, Lausanne

[9] Franz W. (eds) (1995): "Theoretische Ansaetze zur Erklaerung der Arbeitslosigkeit: Wo stehen wir 1995?", Working Paper, CILE, Konstanz.

[10] Fudenberg, D., Levin, D.K. (1996): "Theory of Learning in Games", Draft, September 24, 1996.

[11] Giersch H. (eds) (1996): "Fighting Europe's Unemployment in the 1990s", Springer, Berlin, Heidelberg.

[12] Gersbach, H. and Sheldon, G. (1996): "Structural reforms and their implications for macroeconomic policies", OECD Proceedings, pp.131-167. 
[13] Krugman, P. (1994): "Past and Prospective Causes of High Unemployment", in Reducing Unemployment: Current Issues and Policy Options, A Symposium Sponsored by the Federal Reserve Bank of Kansas City, Wyoming, 49-80.

[14] Layard, R., S.Nickell and R.Jackman (1991): "Unemployment", Oxford University Press, Oxford.

[15] Lindbeck, A. (1996): "The West European Employment", Weltwirtschaftliches Archiv, 609-63\%.

[16] Manzini, P (1998): "Game Theoretic Models of Wage Bargaining", Journal of Economic Surveys.

[17] Minford, P. (1995): "Unemployment in the OECD and Its Remedies", in $H$. Giersch: Fighting Europe's Unemployment in the 1990s, Springer-Verlag, Berlin, Heidelberg.

[18] Nickell, S. (1997): "Unemployment and Labor Market Rigidities: Europe versus North America", Journal of Economic Perspectives, Vol. 11, 55-75.

[19] OECD (1995): "The OECD Jobs Study: Investment, Production and Employment", $O E C D$, Paris.

[20] Oswald, A. (1996): "A Conjecture on the Explanation for High Unemployment in the Industrialised Nations: Part 1", Warwick Economic Research Papers, No. 475, University of Warwick.

[21] Saint-Paul, G. (1994): "Searching for the Virtues of the European Model", Centre for Economic Policy Research, Discussion Paper, 950, 1994/5.

[22] Saint-Paul, G. (1995): "Some Political Aspects of Unemployment", European Economic Review, 39, 575-582.

[23] Schmidt, C.M., Stilz, A., Zimmermann, K.F. (1994): "Mass migration, unions, and government intervention", Journal of Public Economics, 55, 185-201.

[24] Siebert, H. (1997): "At the Root of Unemployment in Europe", Journal of Economic Perspectives, Vol. 11, 37-55.

[25] Young, H.P. (1997): "Microstrategy and Macrostructure", Draft, May 15, 1997. 


\section{IZA Discussion Papers}

\section{No Author(s)}
171 C. Dustmann
F. Windmeijer
172
D. Card

173

174

175

176

O. Hübler

W. Meyer

177 B. R. Chiswick

G. Repetto

178 R. Euwals

M. Ward

179 E. Wasmer

P. Weil

180 T. K. Bauer

I. N. Gang

181 E. Wasmer

Y. Zenou

182 M. Fertig

C. M. Schmidt

183 M. Fertig

C. M. Schmidt

184 M. Corak

B. Gustafsson

T. Österberg

185 H. Bonin

K. F. Zimmermann
Titel

Area

Date

Wages and the Demand for Health - A Life Cycle

5

Analysis

Reforming the Financial Incentives of the Welfare

System

Timing, Togetherness and Time Windfalls

5

$7 / 00$

Does Money Illusion Matter? An Experimental Approach

Self-Employment and Earnings among HighSkilled Immigrants in the United States

Industrial Relations and the Wage Differentials

between Skilled and Unskilled Blue-Collar

Workers within Establishments: An Empirical

Analysis with Data of Manufacturing Firms

Immigrant Adjustment in Israel: Literacy and

Fluency in Hebrew and Earnings

The Renumeration of British Academics

5

$7 / 00$

The Macroeconomics of Labor and Credit Market Imperfections

Sibling Rivalry in Educational Attainment:

The German Case

Space, Search and Efficiency

$8 / 00$

$8 / 00$

Discretionary Measures of Active Labor Market

Policy: The German Employment Promotion Reform in Perspective

Aggregate-Level Migration Studies as a Tool for 1 Forecasting Future Migration Streams

$8 / 00$

Intergenerational Influences on the Receipt of

3

$8 / 00$

Unemployment Insurance in Canada and Sweden

The Post-Unification German Labor Market

4

$8 / 00$ 
A. S. Kalwij

The Myth of Worksharing

A. Zaidi

Is Unemployment Really Scarring? Effects of

The Determination of Wages and the Gender 
220 W. A. Cornelius

E. A. Marcelli

221

C. Grund

222 W.P.M. Vijverberg

223 M. Rosholm

M. Svarer

J. Schwarze

L. Modesto

J. P. Thomas

P. A. Puhani

227

L. Locher
G. Brunello

S. Comi

C. Lucifora
R. Coimbra
T. Lloyd-Braga
L. Modesto

230

L. Modesto

231

G. Saint-Paul

E. Bardasi

M. Francesconi

C. Dustmann

C. M. Schmidt
The Changing Profile of Mexican Migrants to the

Wages as Risk Compensation in Germany

On the Identification of Relative Wage Rigidity Cross-Section Data and Empirical Evidence for Poland in Transition

Immigration from the Eastern Block and the former Soviet Union to Israel: Who is coming when?

The College Wage Gap in 10 European

\section{Fluctuations} and Earnings: An Empirical Study for Portugal 

1969-95 the 1990s

244 S. M. Fuess, Jr. M. Millea

Pay and Productivity in a Corporatist Economy: 
249 B. M. S. van Praag

P. Cardoso

250 T. J. Hatton

J. G. Williamson

251

R. Yemtsov

252

R. Yemtsov

253

R. Yemtsov

254 H. Gersbach

A. Schniewind
"Should I Pay for You or for Myself?"

3

01/01

The Optimal Level and Composition of

Retirement Benefit Systems

Demographic and Economic Pressure on

1

01/01

Emigration out of Africa

Labor Markets, Inequality and Poverty in Georgia

4

$01 / 01$

Inequality and Income Distribution in Georgia

4

$01 / 01$

Living Standards and Economic Vulnerability in

4 Turkey between 1987 and 1994

Learning of General Equilibrium Effects and the Unemployment Trap
$01 / 01$

$02 / 01$ 